Kooperative Informationsinfrastrukturen als Chance und Herausforderung 


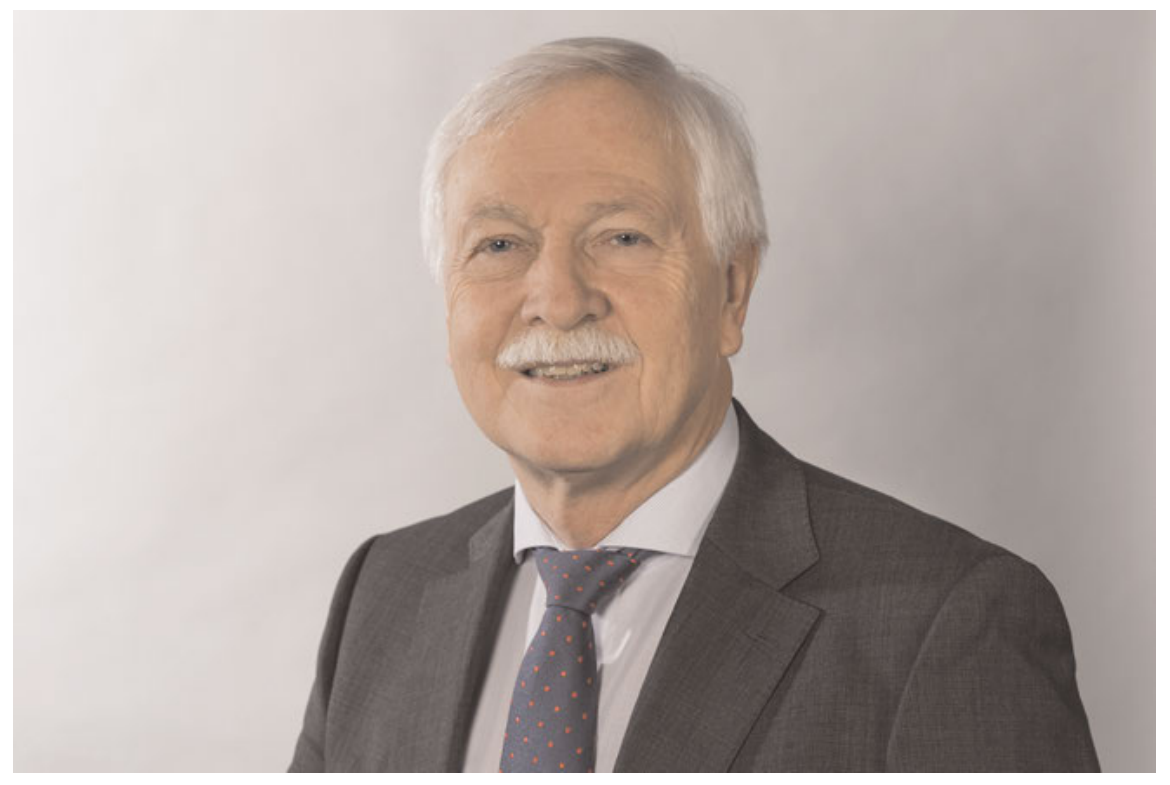




\section{Kooperative Informationsinfrastrukturen als Chance und Herausforderung}

Thomas Bürger zum 65. Geburtstag

Herausgegeben von Achim Bonte und Juliane Rehnolt

\section{DE GRUYTER}

SAUR 


\section{(cc) BY-NC-ND}

Dieses Werk ist lizenziert unter der Creative Commons Attribution- NonCommercialNoDerivatives 4.0 Lizenz. Weitere Informationen finden Sie unter http://creativecommons. org/licenses/by-nc-nd/4.0/.

\section{Library of Congress Cataloging-in-Publication Data}

Names: Bonte, Achim editor.

Title: Kooperative informationsinfrastrukturen als chance und herausforderung : festschrift fuer thomas buerger zum 65. geburtstag / [edited by] Achim Bonte.

Description: Boston, MA : De Gruyter, 2018. Identifiers: LCCN 2018937179 | ISBN 9783110584936 (alk. paper)

Subjects: LCSH: Classification. | Library science-German-speaking countries. | BISAC: LANGUAGE ARTS \& DISCIPLINES / Library \& Information Science / General.

Classification: LCC Z696.A4 K567 2018 | DDC 025.4/2-dc23 LC record available at https://lccn.loc.gov/2018937179

\section{Bibliographic information published by the Deutsche Nationalbibliothek}

The Deutsche Nationalbibliothek lists this publication in the Deutsche Nationalbibliografie; detailed bibliographic data are available on the Internet at http://dnb.dnb.de.

(c) 2018 Achim Bonte und Juliane Rehnolt, publiziert von Walter de Gruyter GmbH, Berlin/Boston

Dieses Buch ist als Open-Access-Publikation verfügbar über www.degruyter.com. Coverabbildung: unter Verwendung von Jürgen Haufe: 0. T., 1999. SLUB Dresden/Deutsche Fotothek. Foto: Klaus-Dieter Schumacher Satz: bsix information exchange $\mathrm{GmbH}$, Braunschweig Druck und Bindung: $\mathrm{CPI}$ books $\mathrm{GmbH}$, Leck 